DOI: 10.17747/TEDS-2020-28-32

Svetlana V. Karpova ${ }^{1}$, Olga E. Ustinova ${ }^{2}$

1Professor of the Logistics and Marketing Department, 2Department of Management Financial University under the Government of the Russian Federation Moscow, Russia

${ }^{1}$ SVKarpova@fa.ru, ${ }^{2}$ OEUstinova@fa

\title{
TRANSFORMATION OF CONSUMER BEHAVIOR IN THE INDUSTRIAL MARKET IN THE CONTEXT OF DIGITALIZATION
}

\begin{abstract}
Intense competition in industrial markets leads to constant changes in consumer behavior. Difficult pricing negotiations and abuse of power make it difficult for participants to interact in sales management. Taking these facts into account, it should be noted that for the sales manager, price becomes an indicator of success in the end result of negotiations. At the same time, surveys of heads of sales departments in the industrial sector show that, among other important elements of negotiations, are the duration of the business relationship, the reputation of the supplier. Despite these tendencies, questions remain about other factors that can consciously or unconsciously influence the negotiation situation, both in a positive and negative direction. The research results were carried out in accordance with the order of the Financial University under the Government of the Russian Federation of March 20, 2020 No. 0564 / o "On the organization of the implementation of the second stage of fundamental research works carried out within the framework of the state assignment in 2020." on the topic "Theory of consumer behavior in the modern economy".
\end{abstract}

Keywords - marketing technologies, procurement, industrial market, consumer behavior, online commerce, formalized interviews, innovative products

\section{INTRODUCTION}

Changes in the socio-economic life of the country have given rise to significant changes in the consumption of manufacturing companies. Saturation of the market with industrial goods provides the possibility of variable satisfaction of needs and an increase in the requirements of various categories of consumers of industrial goods for product quality. The release of products designed for the average level of requirements has become economically unprofitable. In such conditions, the main task of manufacturing companies is to develop products with predetermined standards of consumer properties that best meet the structure of the needs of the target market for industrial goods. Achieving this goal involves establishing feedback channels with consumers and their inclusion in the product quality management system.

\section{LITERATURE REVIEW}

Despite the fact that several decades have passed, in the analysis of industrial business relations, the concepts of the procurement center are actively cited $[8,2,1]$. The conditional grouping of business representatives who participate in making a purchase decision is still associated with functions and organizational distribution [6]. Decision-makers are players who have defined behavioral expectations in the procurement process and who must meet those expectations in more or less strong behavioral patterns (role behavior) [1]. Typical examples are "cost-oriented buyer" or "technology-preferred development project manager". In the context of dynamic development and the international influence of the industrial environment, this classic role-playing concept becomes insufficient. For example, company representatives involved in the procurement process should define organizational functions. In an industrial environment, they often behave differently from what their role is usually understood to be. The traditional approach to the procurement center does not take into account important institutional and individual influencing factors [3]. 
In Germany, Austria and Switzerland, the Sinus-Milieu system, developed by the Sinus Sociovision in Heidelberg, is the most common typology of lifestyles [4]. It classifies target groups according to a detailed analysis of social worlds. The basic idea is that people with the same characteristics, such as age, gender, job, or income, can be categorized into different target groups. Formal similarities or identical social status can be accompanied by completely different views and values. The expectations and buying behavior of these consumers can only be methodically compiled through a holistic analysis of their lifestyles and attitudes [4]. By the late 1970s, Sinus Sociovision presented its results for the first time through quality interviews related to the daily lives of consumers. The indicators of this system classify people according to sociocultural aspects, such as established or modern performer, positioning them according to their lifestyle, i.e. value system and social status.

The limited behavioral relevance in targeting "sociodemographic twins" in the consumer goods sector can be transferred to the identical roles of a single purchasing center function in the industrial goods environment. No two purchasing managers are the same. This means that the shopping center twins can vary greatly in their shopping behavior. Therefore, M. Kuhn and Y. Zajontz [7] carried out micro-segmentation to characterize the different individuals involved in procurement and go beyond the purely structural and functional orientation of the procurement center. The authors divided these so-called industrial lifestyle types into group workshops in which young professionals or trainees from more than 50 industrial companies were invited to share their experience in sales and procurement to define industrial lifestyle types. In addition to functional and hierarchical aspects, typical value principles and characteristics that affect personality were used as segmentation features.

In addition to the different types of industrial lifestyles, other aspects such as the quality and price of the service are important in making industrial purchasing decisions [3]. The duration of the business relationship also influences the buying behavior, as the advantage of the negotiation outcome decreases as the length of the negotiation increases [9].

The use of digital and cloud technologies, on the one hand, led to the growth of the online trading market, on the other hand, they leveled the conditions for all companies, including large, medium and small [5]. Thus, the traditional barriers that prevented small firms from entering global markets have disappeared. This has a corresponding impact on branding processes and the entire trademark ecosystem.

\section{METHODS}

The effective functioning of companies in modern conditions requires a deep analysis of the developments in the market and phenomena. At the stage of searching for the research methodology, the choice was made in favor of interviews. When preparing and conducting research, a methodological apparatus was used that ensures the reliability of scientific results and the reliability of the data obtained. The objects of the research were organizations of large, medium and small businesses. The subject of the research is the behavior of industrial market participants in the procurement process. The aim of the study was to identify the features of consumer behavior in industrial markets in the context of digital transformation.

Based on the use of a qualitative approach, the study determined a sample set of formalized interviews in the amount of 30 respondents, represented by company leaders and managers who procure goods and services. At the same time, the method of forming equal quotas was used: 10 respondents for each type of business, depending on the size of the company. The collection of tools was realized through modern digital technologies (google-forms). In the structure of the respondents, $60.0 \%$ have been working in this position for no more than 10 years, $26.7 \%$ have a similar work experience in the range of 11-20 years and have been purchasing in the industrial market for more than 20 years, $13.3 \%$ of the respondents. At the same time, $96.7 \%$ of interviewers have higher education including an academic degree. 
The systematization and processing of the bulk of the responses received was carried out in accordance with the requirements of ensuring the reliability of sociological and marketing information by summarizing it in a summary table and further highlighting the characteristics of the behavior of participants in the industrial market when making purchases. This allowed the results of the study to be evaluated against standard procedures to ensure the representativeness of the study sample, application and data entry.

\section{DISCUSSION AND RESULTS}

Identifying, examining and selecting a supplier are important elements of procurement. This process may involve a single supplier, several employees, a special process managed by a supervisor. Procurement professionals take different approaches to organizing their work. This is influenced by education received, current age of work, character, willingness to take risks, etc.

Analysis of respondents' answers showed that when using supplier selection solutions, representatives of small businesses rely on situational analysis, management opinions, as well as recommendations and opinions of employees. Mid-sized companies also work with partners with whom they have been working for a long time. Decisions are usually made centrally based on careful analysis of software usage. Large business makes a choice based on "the recommendations of customers, their own experience with suppliers, their reputation." As a rule, the choice of the perfect one on the basis of careful analysis is centralized through the relevant departments. Among the criteria of importance in making purchases, representatives of small businesses rate their own work experience lower (13\%) and give preference, first of all, to the functional characteristics of products, quality assurance and a favorable price offer.

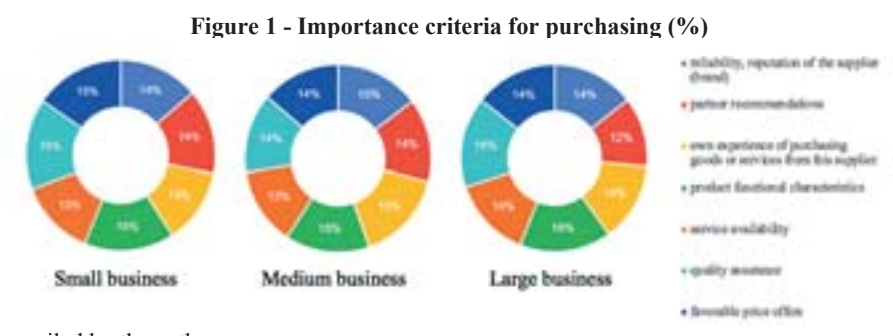

Source: compiled by the authors

On the contrary, medium-sized businesses most of all trust their own experience of purchasing from a specific supplier (15\%) and least of all the availability of service (13\%). For large companies, performance and quality assurance, reliability and supplier reputation are of highest value. Least of all big business trusts recommendations of partners.

In today's highly competitive environment, the ability of companies to create and introduce new products to ensure technological leadership is becoming increasingly important. Since, when purchasing innovative products, companies may not have sufficient information about them, this process, as a rule, involves several sequential stages. At the first stage, the customer company assesses the supplier's reputation, his experience in the execution of similar contracts, clarifies information about the product, etc. At the second stage, technical and commercial requirements are clarified, taking into account alternative proposals from other suppliers. It is important to emphasize that multi-stage procurement procedures for innovative products are provided for by the legislation of different countries. Within the framework of the study, the opinions of managers regarding their preferences in terms of product innovation were not significantly divided. Thus, small and medium-sized businesses mainly rely on wellknown and market-tested products. Large business makes certain requirements for it "the product must meet the technical requirements of the internal customer", sometimes purchasing managers give preference to new innovative products. 
Among the main characteristics of innovative products that affect the reaction of consumers in the industrial market, the following are known:

- the advantage, features or the degree of perception of the new product as the best available analogue;

- compatibility or relevance of the new product with the

- values and practical experience of the manager; complexity as the level of accessibility of the employee's perception of a new product and its use, including technical complexity, fear of rapid moral and physical aging, social reaction; availability of the possibility of trial use of products.

Thus, one of the main features of the procurement of innovative products can be attributed to the lack of clearly established technical characteristics and significant R\&D expenditures, in contrast to known products.

The digitalization of business processes puts forward new requirements for the organization of communication between participants in the industrial market. Thanks to modern technology, it has become possible to create a portfolio of data containing detailed information about the consumer. Thus, both in production and in advertising, it became possible to combine mass production of products and an individual approach to the consumer and his choice. A new ideology has emerged, based on the customer's internal motivation.

The study showed that the parameters of newsletters presented in Figure 2 are important for consumer activity. For respondents of small and medium-sized businesses, the timeliness of information about promotions and discounts, as well as the ability to request additional information, have the highest value on a 5-point scale.

Figure 2 - Parameters of informational advertising mailings Source: compiled by the authors

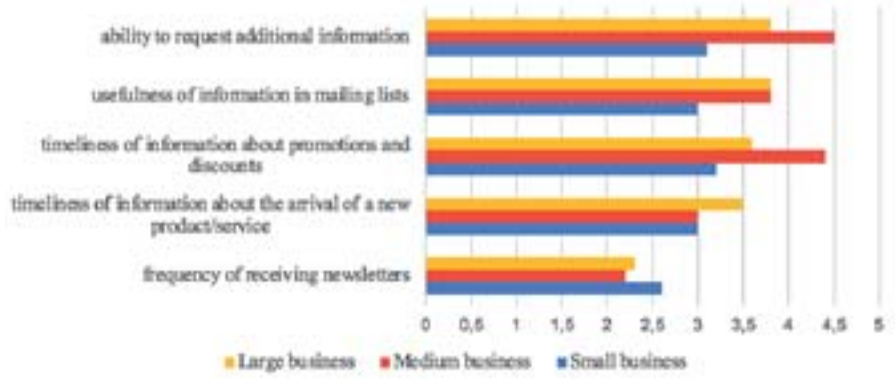

The least importance is attached to the timeliness of information about the arrival of a new product / service. For large companies, important parameters include the usefulness of information in mailings and the ability to query queries. It should be noted that all companies rated the newsletter frequency parameter low. A distinctive feature of the industrial market is the limited number of customers. In this regard, it becomes important to build communications with customers. Digital marketing is proving to be effective with both consumers and businesses. At the same time, it is important to find out what is interesting to consumers of the industrial market, what inspires them or what worries them.

\section{CONCLUTION}

In the digital economy, the study of the characteristics of consumer behavior should help to improve the efficiency of not only procurement, but also the entire financial and economic activities of the company and, as a result, increase its competitiveness. In general, the theory of consumer behavior in industrial markets is developing and enriching under the influence of global civilization 
processes, characterized by the active spread of innovations, advanced digital and production technologies, and the expansion of the geography of customers and suppliers. One of the most significant trends in the transformation of consumer behavior and segmentation is the distribution channels used, based on the active promotion and use of digital technologies.

\section{REFERENCES}

[1] Backhaus, K., \& Voeth, M. (2010). Industriegütermarketing. Munich: Vahlen.

[2] Hutt, M. D., \& Speh, T. W. (2004). Business marketing management: A strategic view of industrial and organizational markets. London: Thomson.

[3] Homburg, C. (2012). Marketingmanagement: Strategie - Instrumente - Umsetzung Unternehmensführung. Heidelberg: Gabler.

[4] Kalka, J., \& Allgayer, F. (2006). Zielgruppen —wie sie leben, was sie kaufen, woran sie glauben. Moderne Industrie: Landsberg am Lech.

[5] Karpova S.V., Ustinova O.E. (2019). Brend kak instrument marketinga: vliyanie na povedenie potrebitelej. Risk: resursy, informaciya, snabzhenie, konkurenciya. (4). 68-73. (in Russian).

[6] Kennedy, A. (1982). Industrial buying behaviour: A review of literature and research needs. Management Decision, 20, 38-51.

[7] Kuhn, M., \& Zajontz, Y. (2011). Industrielles Marketing. Munich: Oldenbourg.

[8] Roth, S. (2006). Preismanagement für Leistungsbündel. Wiesbaden: Deutscher Universitätsverlag.

[9] Webster, F. E. J., \& Wind, Y. (1972). Organizational buying behavior. Englewood Cliffs, NJ: Prentice Hall. 